\title{
What skills do volunteer leaders need? A Delphi study
}

\author{
Carley C. Morrison \\ Visiting Assistant Professor \\ Mississippi State University \\ Laura L. Greenhaw \\ Assistant Professor \\ Mississippi State University
}

\begin{abstract}
Non-profit and volunteer-based organizations are tasked with meeting the needs of their communities with limited resources. Today, more than ever, these organizations are stretched to their limits increasing the workload for paid staff. Training volunteers to lead the volunteer efforts is one way to spread the workload throughout the organization. Although there are guidelines for leadership development in for-profit organizations, there is limited literature pertaining to specific competencies and skills volunteer leaders in nonprofit and volunteer-based organizations should possess. This study, employing Delphi methodology, was conducted with volunteer directors in the community to identify leadership competencies for volunteer leaders. At the conclusion of three rounds of iteration, 42 competencies were identified.
\end{abstract}

\section{Introduction/Literature Review}

Nonprofit volunteers and for-profit employees differ in their reasoning and motivation for engaging in their respective jobs (Boezeman \& Ellemers, 2014; Cnaan \& Cascio, 1999; Pearce, 1993). For this reason, leadership styles directed at for-profit organizations are not appropriate for nonprofit organizations (Farmer \& Fedor, 2001). Moreover, the traditional single leader model is becoming less effective as the demands of nonprofit organizations increase. Small (2007) suggests

"Traditionally, leadership theories have focused on vertical leadership, in which a person who has been appointed to a position of authority exerts downward influence on subordinates. However, appointed leaders are not the only ones who can demonstrate leadership behavior. In team situations, team members can exert influence on each other and share the leadership process." (p. 5)

The transition toward team work structures, particularly in capacity-limited nonprofit organizations, can present a challenge in providing the leadership necessary to achieve organizational success. Volunteer-based organizations must identify ways to provide the requisite leadership for their volunteers to accomplish personal and organizational goals.

"Volunteer leadership remains a vast untapped resource for nonprofits not only to expand capacity for service and volunteering but also to provide a strategy for addressing 
the retention challenge facing volunteer managers...In addition, these leadership roles, if properly supported, cultivate the consciousness, capabilities, and commitment in volunteers, and create lifelong advocates for causes and the change that citizens seek to make in their communities." (Cooperation, 2007b, p. 15).

Programs led by volunteers have a greater impact on communities (Texas AgriLife, n.d). Nonprofit organizations provide opportunities for individuals to give back to their community. However, retaining those volunteers is a challenge faced by nonprofit organizations across the globe. At times the volunteer can be less invested in the mission of the organization than the paid staff, causing the volunteer to leave rather than return to work towards a common goal (Cooperation, 2007b). According to the Cooperation of National and Community Service (2007a) "one out of three volunteers who volunteer in one year do not volunteer the next year" (p. 1).

Northouse (2013) describes leadership as "a process whereby an individual influences a group of individuals to achieve a common goal” (p. 5). Boyd (2003) revealed numerous competencies and skills leaders of nonprofit organizations should possess to effectively facilitate the operation of the organization. Some of these competencies include: organizational leadership, systems leadership, organizational culture, personal skills, and management skills (Boyd, 2003). However, this study focused on paid nonprofit administrators and directors as the leaders of the nonprofit organization. Tuckey, Bakker, and Dollard (2012) state there is limited literature specific to volunteer leader competencies, identification of volunteer leaders, and the outcome of volunteer leadership on the organization as a whole.

Conger (1999) was one of the first researchers to separate the roles of organizational leaders and managers. Moreover, transactional leadership used to be the driving force behind leadership development efforts, however now the attention is on transformational leadership. Transformational leadership has the ability to influence followers on a deeper level and gives them a sense of higher purpose, leads to greater organizational commitment, and instigates trust through confidence and conviction (Hernez- Broome \& Hughes, 2004). Topics such as, a leader's emotional connectedness, authenticity, credibility, and trustworthiness have all gained the attention of researchers as leadership development continues to gain popularity in academia (Sankar, 2003; Goleman \& Boyatzis 2002; Collins, 2001).

In terms of evaluating volunteer leaders' competencies and skills, there has been a shift from direct feedback from the director to more of a 360-degree evaluation (Culp, Brown, Hall, McDonough, Ragland, Weaver, \& Whitson, 2009; Hernez-Broome, $\&$ Hughes,2004). This type of evaluation requires multiple people from all levels of the organization to provide feedback on one person's ability to perform a task (Culp et al., 2009). The benefits of this type of assessment, compared to traditional methods, include: enhanced communication between all parties, clearer understanding of roles and expectations, a stronger organization or program, better utilization of the leaders skills, increased leader self-esteem, and increased retention of the leader (Culp et al., 2009). Moreover, this assessment method requires a short turnaround from evaluation to feedback. "Therefore, the evaluation instrument must be simple enough to require little 
orientation, so that individuals will easily understand how to complete it" (Culp et al., 2009, para. 6).

Volunteer leaders differ from the paid nonprofit administrators or directors in that a volunteer leader is a non-paid individual with a formally defined role within the organization. A volunteer leader takes charge and ownership in coordinating projects and programs that build community assets, meet community needs, and provide volunteers with a positive experience so that they continue their journey of service while helping to carry out the mission of the non-profit organization (Jamey Bachman, personal communication, February 9, 2016). As demands on nonprofit organizations continue to increase, volunteer leaders will have to step-up and assume more responsibility to ease the workload of the paid directors and administrators. the purpose was to gain consensus from experts on necessary volunteer leader skills and competencies. The following objective guided this study:

1. Define the competencies and skills desired by directors and administrators in volunteer leaders of nonprofit organizations.

\section{Methods}

The Delphi method was used to determine specific competencies desired in a volunteer leader. A Delphi study asks the opinions of experts in the field of study through multiple rounds of survey instrumentation (Linstone \& Turoff, 2002). The questionnaires are designed to allow the experts to hone their responses in multiple rounds compared to the responses of the other experts in the panel (Adler \& Ziglio, 1996). The Delphi method originated from a study conducted by the Rand Corporation in the 1950s known as "Project Delphi" which pursued the opinions of experts (Pierce, 2007). This method was selected to obtain consensus regarding unique competencies and skills of effective volunteer leaders in non-profit organizations using directors from a diverse collection of non-profit organizations across the nation.

To insure anonymity, none of the participants' responses were linked to them by name. This essential feature of the Delphi method levels the field of panelists and reduces the influence of others on individual responses (Gines-Rivera, 2010). Multiple rounds of instrumentation allow participants to independently form, and revise, their responses slowly over a period of time (Rowe \& Wright, 1999). Figure 1 displays the Delphi methodology as a controlled flow of information involving a logical series of questionnaires and feedback to panel participants after each round of iteration. 
Phase One Problem

Identified Expert Panel

Identified Instrument

Development

Data Collected and Analyzed

\section{Phase Two}

Instrument Two is Developed and Fed Back to Panel

Data Collected and Analyzed

\section{Phase Three}

Instrument Three is Developed and Fed Back to Panel

Data Collected and Analyzed

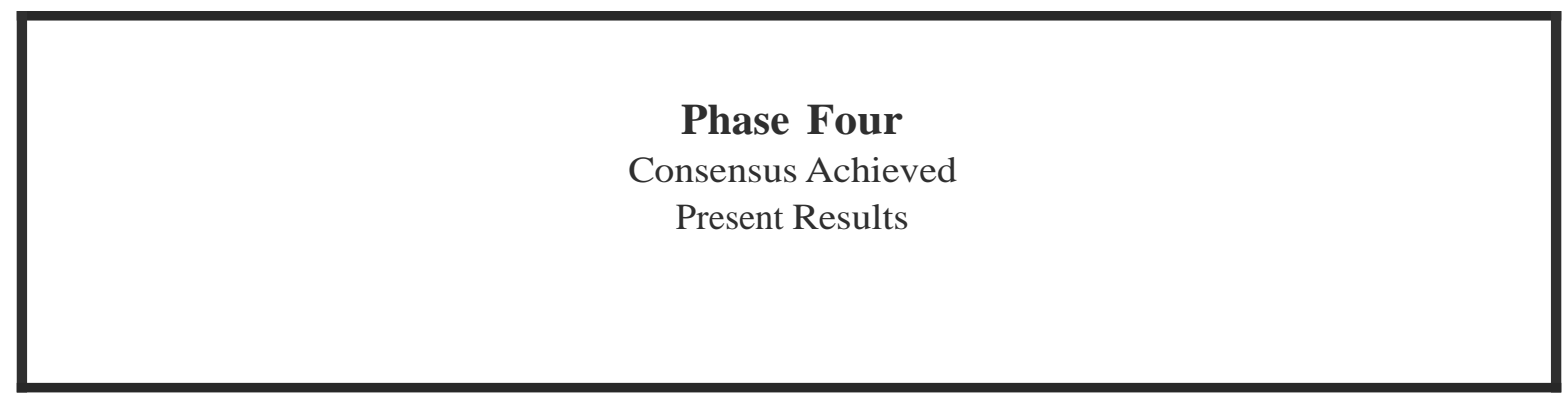

Figure 1. Steps for conducting a Delphi study. 


\section{Delphi Sample}

There is no rule of thumb for how many panelists should be included in a Delphi study (Mullen, 2003). However, researchers have expressed concerns about "bias resulting from low response rates and high attrition rates" (Mullen, 2003, pg. 41). It is recommended that a $70 \%$ response rate between iterations should be achieved to maintain statistical rigor (Bradfor, 1996). In addition, Reid (as cited in Mullen, 2003) notes that larger panels increase the drop-out rate, suggesting panels of 20 tend to retain their numbers.

This process involved a snowball sample of directors in various non-profit volunteer organizations representing Starkville, Mississippi, area affiliates of local, state, and national non-profit and volunteer-based organizations. The first round began with a contact list of 150 directors provided by Habitat for Humanity, in Starkville, Mississippi. At the conclusion of the first-round instrumentation, respondents were asked to provide a list of additional experts (Hsu \& Sandford, 2007; Ludwig, 1994). The additional contacts were added to the 150 directors from the first-round email list for rounds two and three.

The Delphi participants were selected for their expertise in the field, as well as, "a related interest in the topic being examined and a willingness to commit and participate in the research study" (Gines-Rivera, 2010, p. 53). Selecting the experts to participate in the Delphi is regarded by many as the most important step of the process because of their influence on the strength of the study (Gines-Rivera, 2010; Hsu \& Sandford, 2007; Yousuf, 2007a; Gordon \& Pease, 2006; Okoli \& Pawlowski, 2004; Dawson \& Brucker, 2001). The panelists for the Delphi study were contacted via e-mail to obtain consent to participate in each round of iteration. All identifying information pertaining to the panelists remained confidential.

\section{Delphi Instrumentation, Data Collection, and Analysis}

Panelists' opinions were gathered over three rounds of iteration using researcher developed questionnaires with open ended and rank order questions. The questionnaires were administered through Qualtrics online survey software. The number of rounds conducted in a Delphi study is dependent upon the desired outcomes of the research and the make-up of the panelists (Gines-Rivera, 2010; Skulmoski, Hartman, \& Krahn, 2007). However, the more rounds conducted, the higher the drop-out rate of the participants (Skulmoski et al., 2007). Three rounds were used in this study. Before the panel responded to each round of iteration they were informed about the scope of the study and any risks associated with participating. The panelists indicated their voluntary consent to participate by completing each instrument.

Round one questionnaire asked respondents 1) In a volunteer organization, what are the most important leadership competencies a volunteer leader should possess?, and 2) In a volunteer organization, how should volunteer leaders be assessed on these leadership competencies? The two initial questions were followed by a place for respondents to report their names, organizations, and titles. Demographic information was collected only to determine who responded to multiple rounds of iteration during the data collection period. Participants were given two weeks to respond to round one of the Delphi. 
To increase participation, an email reminder was sent one week after the first questionnaire was distributed to the panel (Dillman, 2011). Results from the first round questionnaire were analyzed three weeks after first contact was made. A list of volunteer leadership competencies was compiled from the responses, along with a list of how they should be assessed. Similar terminology was combined to a common competency (Schmidt, 1997). The initial questions were distributed to the additional contacts provided by the experts and the same procedure was followed to compile one list from the first round of the Delphi study. A total of 20 experts participated in the first round.

The questionnaire for the second round of the Delphi was developed from the responses on the round one questionnaire (Skulmoski et al., 2007). This questionnaire listed the competencies and assessment techniques identified in the first round in descending order with the most common competency or assessment technique listed first and the least common listed last. During the second round, the participants were asked to confirm, assess, and reevaluate their initial responses. In addition, the 20 panelists were then asked to indicate at what level they agreed with each competency using a 5-point rating scale where $5=$ "strongly agree" and $1=$ "Strongly disagree". All participants were then asked to make additional suggestions of competencies not included in the round two list (Okoli \& Pawlowski, 2004). To increase participation, an email reminder was sent one week after the second questionnaire was distributed to the panel (Dillman, 2011). At the conclusion of round two, 16 respondents participated.

The results of round two were analyzed three weeks after the questionnaire was administered. For this study, consensus on a competency was defined by a mean value of 4 or higher on the 5-point rating scale (Mayberry, 2009). Descriptive statistics (means, median, mode, and standard deviation) were used to analyze round two. The same procedures and data analysis methods were used for round three of the Delphi, with the exception of the option to add additional competencies. Round three was distributed to the 20 original respondents with a response rate of $100 \%$. At the conclusion of round three, the statistical average of the opinions were calculated to ensure the views of every panelist were reflected (Yousuf, 2007b). At the conclusion of three rounds of iteration, 42 competencies were identified.

\section{Results}

\section{Round I}

Panelists $(\mathrm{n}=20)$ produced a list of 82 competencies and skills volunteer leaders should possess. Similar terminology was combined into a single term and a list of 45 competencies was produced as a result of round one as seen in Table 1. Several competencies and skills were repeated by multiple respondents. 
Table 1

Results of Delphi I: Competencies volunteer agencies desire in volunteer leaders

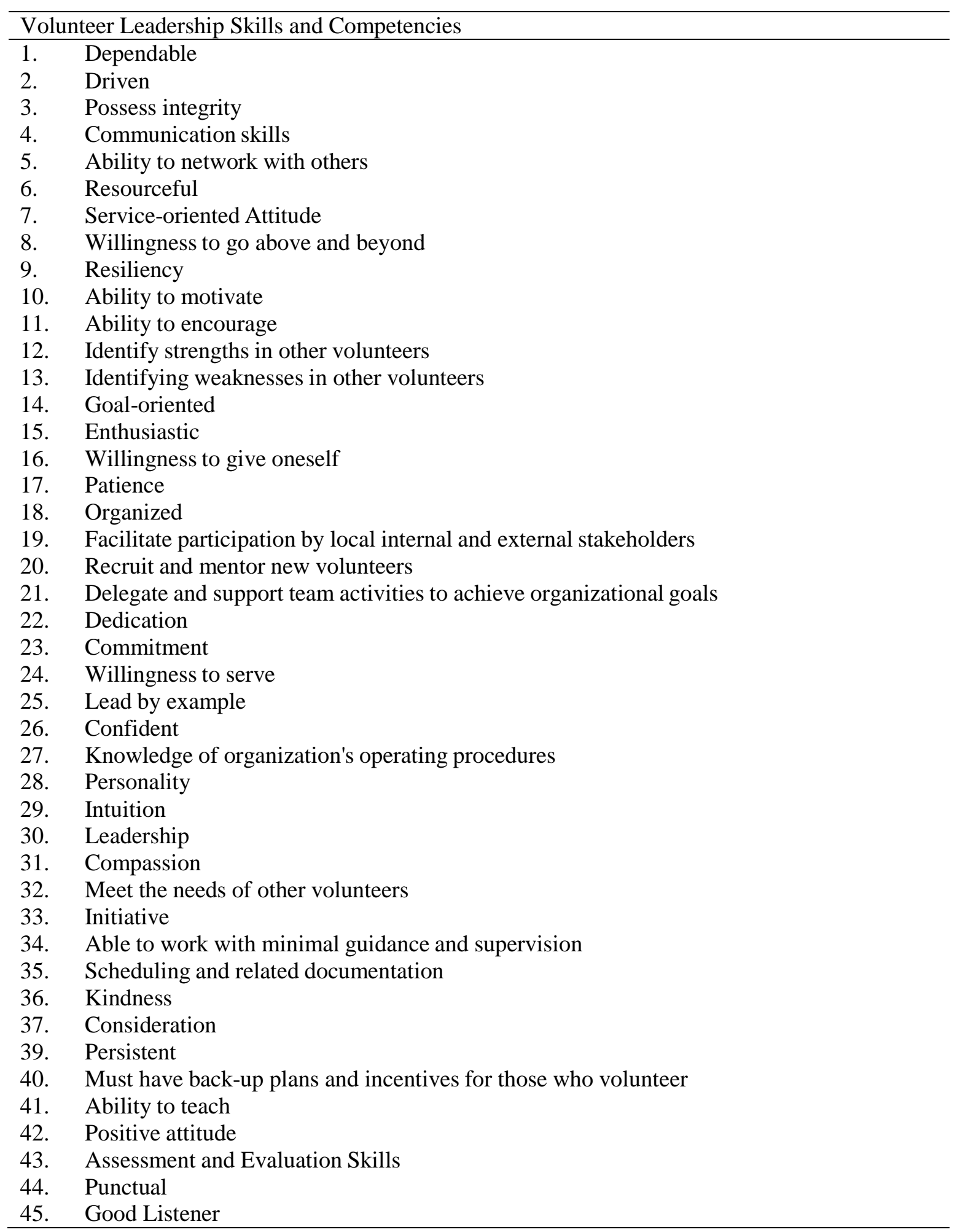

Note. Items are listed in order from most frequent to least frequent. 
Additionally, panelists provided 18 ways to assess volunteer leaders on their ability to demonstrate the identified leadership competencies. Some measures of assessment were only recorded by one respondent while others were repeated by multiple panelists. The responses were combined to reflect 16 independent assessment measures listed in Table 2.

Table 2

Results of Delphi I: In a volunteer organization, how should volunteer leaders be assessed on these leadership competencies?

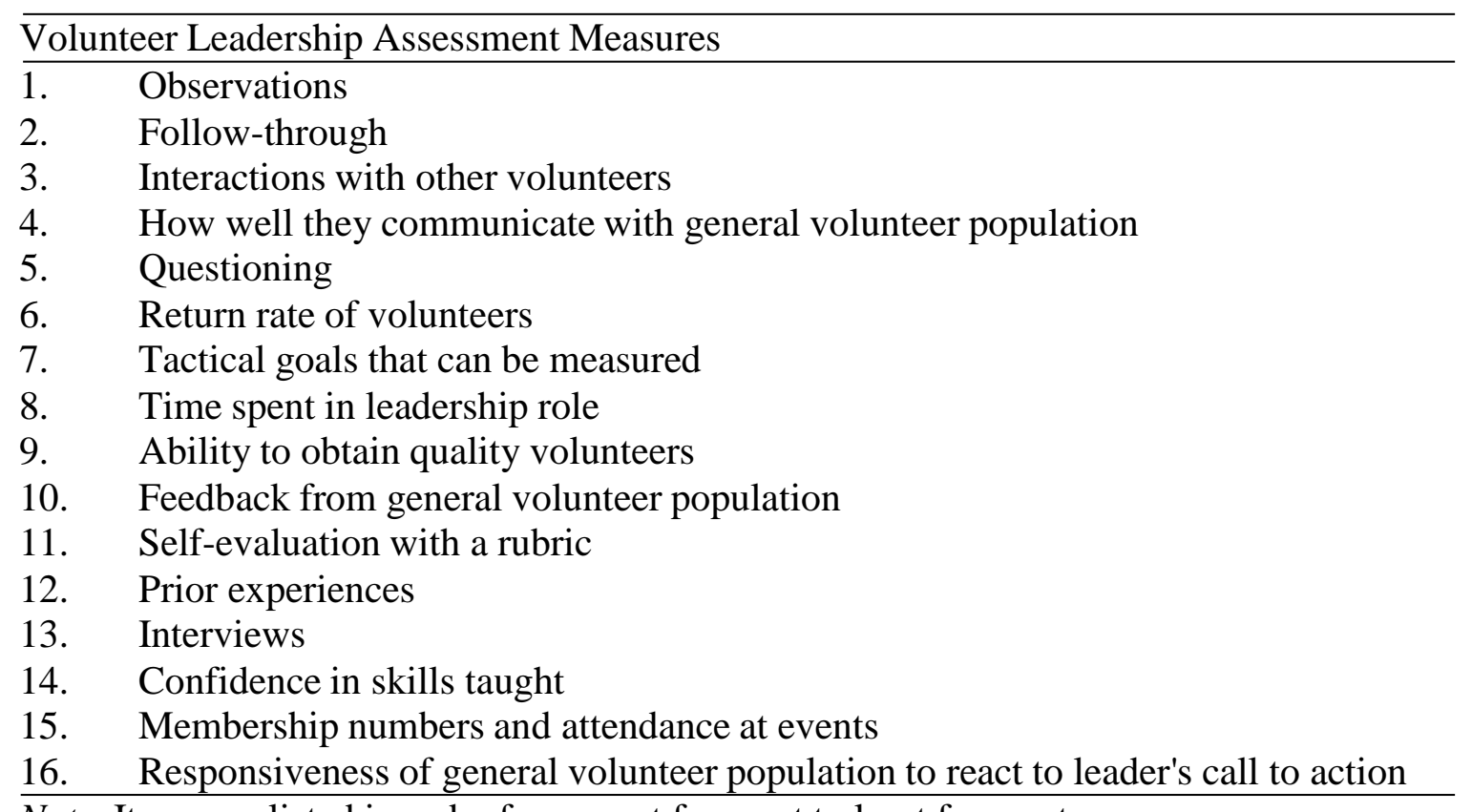

Note. Items are listed in order from most frequent to least frequent.

\section{Round II}

The instrument used for the second round of the Delphi was developed from the list of leadership competencies and skills, and assessment measures identified by the panel of experts in the first round. The items were listed under their corresponding question with a 5-point rating scale where $1=$ very unimportant, $2=$ unimportant, $3=$ neither important nor unimportant, 4 = important, and 5 = very important. Respondents were also given the opportunity to provide additional responses to each question.

An email link to the round-two online questionnaire was sent using the initial listserv with the addition of contacts provided by the round one respondents. Panelists were asked to respond within three weeks for the second round. A reminder email was sent after one week to encourage participation. Sixteen panelists participated in round II $(n=16)$.

Analysis of round two data indicated that all competencies met the original criteria 
of a mean of 4 to be included in round three of the Delphi. In order to pare down the list of competencies, the cut off mean was increased to 4.25 or greater. The descriptive statistics for each item included in the Delphi II are listed in Table 3.

Table 3

Results of Delphi II: Descriptive statistics of leadership competencies and skills that volunteer leaders need to successfully lead volunteer groups

\begin{tabular}{|c|c|c|c|c|c|}
\hline \multicolumn{2}{|r|}{ Volunteer Leadership Skills and Competencies } & \multirow{2}{*}{$\begin{array}{l}N \\
16\end{array}$} & \multirow{2}{*}{\begin{tabular}{c|}
$M$ \\
5.00
\end{tabular}} & \multirow{2}{*}{$\begin{array}{c}S D \\
0.00\end{array}$} & \multirow{2}{*}{$\frac{\text { Mode }}{5}$} \\
\hline 1. & Dependable & & & & \\
\hline 2. & Patience & 16 & 4.75 & 0.45 & 5 \\
\hline 3. & Service-oriented attitude & 16 & 4.75 & 0.58 & 5 \\
\hline 4. & Driven & 16 & 4.69 & 0.48 & 5 \\
\hline 5. & Possess integrity & 16 & 4.69 & 0.48 & 5 \\
\hline 6. & Positive attitude & 16 & 4.69 & 0.48 & 5 \\
\hline 7. & $\begin{array}{l}\text { Delegate and support team activities to achieve } \\
\text { organizational goals }\end{array}$ & 16 & 4.63 & 0.50 & 5 \\
\hline 8. & Lead by example & 16 & 4.63 & 0.50 & 5 \\
\hline 9. & Punctual & 16 & 4.63 & 0.50 & 5 \\
\hline 10. & Resourceful & 16 & 4.63 & 0.50 & 5 \\
\hline 11. & Respect for others & 16 & 4.63 & 0.50 & 5 \\
\hline 12. & Commitment & 16 & 4.56 & 0.51 & 5 \\
\hline 13. & Compassion & 16 & 4.56 & 0.51 & 5 \\
\hline 14. & Good Listener & 16 & 4.56 & 0.51 & 5 \\
\hline 15. & Able to work with minimal guidance and supervision & 16 & 4.56 & 0.63 & 5 \\
\hline 16. & Organized & 16 & 4.56 & 0.63 & 5 \\
\hline 17. & Recruit and mentor new volunteers & 16 & 4.53 & 0.64 & 5 \\
\hline 18. & Initiative & 16 & 4.50 & 0.63 & 5 \\
\hline 19. & Willingness to serve & 16 & 4.50 & 0.63 & 5 \\
\hline 20. & Communication skills & 16 & 4.50 & 0.52 & 4.5 \\
\hline 21. & Consideration & 16 & 4.50 & 0.52 & 4.5 \\
\hline 22. & Dedication & 16 & 4.50 & 0.52 & 4.5 \\
\hline 23. & Kindness & 16 & 4.50 & 0.52 & 4.5 \\
\hline 24. & Knowledge of organization's operating procedures & 16 & 4.50 & 0.52 & 4.5 \\
\hline 25. & Ability to teach & 16 & 4.44 & 0.63 & 5 \\
\hline 26. & Leadership & 16 & 4.44 & 0.63 & 5 \\
\hline 27. & Identify strengths in other volunteers & 16 & 4.44 & 0.73 & 5 \\
\hline 28. & Willingness to give oneself & 16 & 4.44 & 0.73 & 5 \\
\hline 29. & Ability to encourage & 16 & 4.44 & 0.51 & 4 \\
\hline 30. & Persistent $^{+}$ & 15 & 4.40 & 0.51 & 4 \\
\hline 31. & Assessment and Evaluation Skills & 16 & 4.38 & 0.89 & 5 \\
\hline 32. & Confident & 16 & 4.38 & 0.50 & 4 \\
\hline & Willingness to go above and beyond & 16 & 4.34 & 0.63 & 5 \\
\hline 34. & Scheduling and related documentation & 16 & 4.31 & 0.79 & 5 \\
\hline
\end{tabular}

Note. Based on a 5-point rating scale with $5=$ very important and $1=$ very unimportant.

Note. + indicates an item combined with a like term and eliminated.

Note. $*$ indicates items eliminated due to an $\mathrm{M}<4.25$. 
Dependability was the most important competency identified by panelists in round II $(\mathrm{M}=5.00, \mathrm{SD}=0.00$, Mode $=5)$. Patience and a service-oriented attitude followed as also being important competencies for a volunteer leader to possess $(\mathrm{M}=4.75, \mathrm{SD}=0.45$, Mode = 5); $(\mathrm{M}=4.75, \mathrm{SD}=0.58$, Mode = 5). The panel rated: identifying weaknesses in other volunteers, intuition, meet the needs of other volunteers, and goal-oriented as the least important competencies and skills, therefore eliminating them from the Delphi III (M $=4.19, \mathrm{SD}=0.75$, Mode $=4) ;(\mathrm{M}=4.13, \mathrm{SD}=0.72$, Mode $=4) ;(\mathrm{M}=4.13, \mathrm{SD}=0.81$, Mode =4); $(M=4.06, S D=1.00$, Mode =4). Additionally, the item persistent $(M=4.40$, $\mathrm{SD}=0.51$, Mode $=4$ ) was combined with patience to form one item. Respondents listed conflict resolution, critical thinking, and trustworthiness as additional terms for round three.

Trustworthiness was combined with possess integrity, and conflict resolution and critical thinking were added to the round three instrument for a total of 42 items. With regards to what measures should be used to assess volunteers' leadership competencies and skills, the panelists indicated nine of the 16 items were very important. The panelists rated tactical goals that can be measured $(\mathrm{M}=4.19, \mathrm{SD}=0.66$, Mode $=4)$, membership numbers and attendance at events $(\mathrm{M}=4.19, \mathrm{SD}=0.83$, Mode $=4)$, questioning $(\mathrm{M}=4.06, \mathrm{SD}=0.68$, Mode $=4)$, self-evaluation with a rubric $(\mathrm{M}=3.88, \mathrm{SD}$ $=0.62$, Mode $=4)$, prior experience $(\mathrm{M}=3.81, \mathrm{SD}=0.75$, Mode $=4)$, time spent in leadership role $(\mathrm{M}=3.81, \mathrm{SD}=0.75$, Mode $=4)$, and interviews $(\mathrm{M}=3.81, \mathrm{SD}=0.83$, Mode $=4$ ) below a mean value of 4.25 , therefore those items were removed from the third round of the Delphi study. There were no additional assessment measures listed by the respondents, therefore no items were added to instrument for round three of the Delphi. Table 4 displays the descriptive statistics for the assessment measures. 
Table 4

Results of Delphi II: Descriptive statistics for measures of assessing leadership competencies and skills in volunteer leaders

\begin{tabular}{|c|c|c|c|c|}
\hline Volunteer Leadership Assessment Measures & $N$ & $M$ & $S D$ & Mode \\
\hline 1. Confidence in skills taught & 16 & 4.56 & 0.5 & 5 \\
\hline 2. Follow-through & 16 & 4.56 & 0.5 & 5 \\
\hline 3. How well they communicate with general volunteer population & 16 & 4.56 & 0.6 & 5 \\
\hline 4. Interactions with other volunteers & 16 & 4.56 & 0.6 & 5 \\
\hline $\begin{array}{l}\text { 5. Responsiveness of general volunteer population to } \\
\text { react to leader's call to action }\end{array}$ & 16 & 4.50 & 0.6 & 4 \\
\hline 6. Ability to obtain quality volunteers & 16 & 4.44 & 0.6 & 5 \\
\hline 7. Observations & 16 & 4.44 & 0.5 & 4 \\
\hline 8. Return rate of volunteers & 16 & 4.38 & 0.6 & 4 \\
\hline 9. Feedback from general volunteer population & 16 & 4.31 & 0.60 & 4 \\
\hline 10. Tactical goals that can be measured* & 16 & 4.19 & 0.66 & 4 \\
\hline 11. Membership numbers and attendance at events* & 16 & 4.19 & 0.83 & 4 \\
\hline 12. Questioning* & 16 & 4.06 & 0.68 & 4 \\
\hline 13. Self-evaluation with a rubric* & 16 & 3.88 & 0.62 & 4 \\
\hline 14. Prior experiences* & 16 & 3.81 & 0.75 & 4 \\
\hline 15. Time spent in leadership role* & 16 & 3.81 & 0.75 & 4 \\
\hline 16. Interviews* & 16 & 3.81 & 0.83 & 4 \\
\hline
\end{tabular}

Note. Based on a 5-point rating scale with $5=$ very important and $1=$ very unimportant. Note. * indicates items eliminated due to a $\mathrm{M}<4.25$

\section{Round III}

The items from round II that met the adjusted criteria of a mean of 4.25 or higher were listed in random order to formulate the Delphi III instrument. The panel of experts were again asked to rate the remaining competencies and assessment measures on a sale of 1 to 5 where $1=$ very unimportant, $2=$ unimportant, $3=$ neither important nor unimportant, $4=$ important, and $5=$ very important. The instrument contained 42 competencies and skills and nine assessment measures.

An email with the link to the round-three online questionnaire was sent using the initial listserv with the addition of contacts provided by the round two respondents. Panelists were asked to respond within three weeks for the third round. A reminder email was sent after one week to encourage participation. 20 panelists participated in round III, however, two respondents were deemed outliers and removed from the study leaving 18 panelists $(\mathrm{n}=18)$.

For data analysis, the original removal criteria of a mean value of 4 was reinstated for the final round of the Delphi study. Based on this criterion the panel of experts reached consensus on all 42 leadership competencies and skills. Table 5 lists the ratings and descriptive statistics for the competencies and skills, in rank order. 
Table 5

Results of Delphi III: Descriptive statistics from panelists who rated the leadership competencies and skills that volunteer leaders need to lead volunteer groups

\begin{tabular}{|c|c|c|c|c|}
\hline Volunteer Leadership Skills and Competencies & $N$ & $M$ & $S D$ & Mode \\
\hline 1. Dependable & 18 & 4.94 & 0.24 & 5 \\
\hline Respect for others & 18 & 4.78 & 0.43 & 5 \\
\hline Good Listener & 18 & 4.72 & 0.46 & 5 \\
\hline Commitment & 18 & 4.67 & 0.49 & 5 \\
\hline Positive Attitude & 17 & 4.65 & 0.49 & 5 \\
\hline Able to work with minimal guidance and supervision & 18 & 4.61 & 0.61 & 5 \\
\hline Communication skills & 18 & 4.61 & 0.50 & 5 \\
\hline Punctual & 18 & 4.61 & 0.50 & 5 \\
\hline Consideration & 18 & 4.56 & 0.51 & 5 \\
\hline 10. Service-oriented Attitude & 18 & 4.56 & 0.51 & 5 \\
\hline 11. Knowledge of organization's operating procedures & 18 & 4.56 & 0.62 & 5 \\
\hline 12. Ability to encourage & 18 & 4.50 & 0.51 & 5 \\
\hline 13. Dedication & 18 & 4.50 & 0.51 & 5 \\
\hline 14. Initiative & 18 & 4.50 & 0.51 & 5 \\
\hline 15. Kindness & 18 & 4.50 & 0.51 & 5 \\
\hline 16. Possess integrity & 18 & 4.50 & 0.51 & 5 \\
\hline 17. Willingness to serve & 18 & 4.50 & 0.62 & 5 \\
\hline 18. Willingness to go above and beyond & 17 & 4.49 & 0.69 & 4 \\
\hline 19. Conflict Resolution & 18 & 4.44 & 0.51 & 4 \\
\hline 20. Organized & 18 & 4.44 & 0.51 & 4 \\
\hline 21. Compassion & 18 & 4.44 & 0.62 & 5 \\
\hline 22. Leadership & 18 & 4.44 & 0.62 & 5 \\
\hline 23. Recruit and mentor new volunteers & 18 & 4.44 & 0.62 & 5 \\
\hline 24. Resourceful & 18 & 4.44 & 0.62 & 5 \\
\hline 25. Willingness to give oneself & 18 & 4.44 & 0.62 & 5 \\
\hline 26. Identify strengths of other volunteers & 18 & 4.44 & 0.70 & 5 \\
\hline 27. Resiliency & 18 & 4.44 & 0.70 & 5 \\
\hline 28. Patience & 17 & 4.41 & 0.51 & 4 \\
\hline 29. Ability to teach & 18 & 4.39 & 0.61 & 4 \\
\hline 30. Critical thinking & 18 & 4.39 & 0.61 & 4 \\
\hline 31. Delegate and support team activities & 18 & 4.39 & 0.61 & 4 \\
\hline 32. Lead by Example & 18 & 4.39 & 0.61 & 4 \\
\hline 33. Ability to motivate & 17 & 4.35 & 0.49 & 4 \\
\hline 34. Enthusiastic & 17 & 4.35 & 0.61 & 4 \\
\hline 35. Ability to network with others & 18 & 4.33 & 0.69 & 5 \\
\hline 36. Personality & 18 & 4.33 & 0.69 & 5 \\
\hline 37. Scheduling and related documents & 18 & 4.28 & 0.75 & 4 \\
\hline 38. Driven & 18 & 4.22 & 0.65 & 4 \\
\hline 39. Must have back-up plans and incentives & 18 & 4.22 & 0.81 & 5 \\
\hline 40. Assessment and evaluation skills & 18 & 4.17 & 0.71 & 4 \\
\hline 41. Facilitate participation by local stakeholders & 18 & 4.17 & 0.71 & 4 \\
\hline 42. Confident & 17 & 4.06 & 0.75 & 4 \\
\hline
\end{tabular}

Note. Based on a 5-point rating scale with $5=$ very important and $1=$ very unimportant. 
As in round two, dependability received the highest rating in round three $(\mathrm{M}=$ 4.94, $\mathrm{SD}=0.24$, Mode $=5$ ). Respondents also rated respect for others and good listener as competencies and skills that are important for volunteer leaders to possess $(\mathrm{M}=4.78, \mathrm{SD}$ $=0.43$, Mode $=5) ;(\mathrm{M}=4.72, \mathrm{SD}=0.46$, Mode $=5)$. Confident, facilitate participation by local internal and external stakeholders, and assessment and evaluation skills received the lowest rating, but still met the original criteria for consensus among the panel of experts $(\mathrm{M}=4.06, \mathrm{SD}=0.75$, Mode $=4) ;(\mathrm{M}=4.17, \mathrm{SD}=0.71$, Mode $=4) ;(\mathrm{M}=4.17, \mathrm{SD}=$ 0.71 , Mode $=4)$.

The panel of experts also reached consensus on all nine measures for assessing volunteers' leadership skills and competencies. Follow-through received the highest rating as being the most important measure for assessing volunteers' leadership skills and competencies $(\mathrm{M}=4.83, \mathrm{SD}=0.38$, Mode $=5)$. The descriptive statistics for all measures of assessment are listed in Table 6.

Table 6 Results of Delphi III: Descriptive statistics from panelists who rated the measures of assessing leadership competencies and skills in volunteer leaders

\begin{tabular}{|c|c|c|c|c|}
\hline Volunteer Leadership Assessment Measures & $N$ & $M$ & $S D$ & Mode \\
\hline Follow-through & 18 & 4.83 & 0.38 & 5 \\
\hline Ability to obtain quality volunteers & 18 & 4.67 & 0.49 & 5 \\
\hline $\begin{array}{l}\text { How well they communicate with general volunteer } \\
\text { population }\end{array}$ & 18 & 4.61 & 0.50 & 5 \\
\hline Return rate of volunteers & 18 & 4.50 & 0.51 & 5 \\
\hline Interactions with other volunteers & 18 & 4.44 & 0.51 & 4 \\
\hline $\begin{array}{l}\text { Responsiveness of general volunteer population to } \\
\text { react to leader's call to action }\end{array}$ & 18 & 4.39 & 0.50 & 4 \\
\hline Confidence in skills taught & 18 & 4.33 & 0.49 & 4 \\
\hline Feedback from general volunteer population & 18 & 4.33 & 0.49 & 4 \\
\hline 9. Observations & 18 & 4.33 & 0.59 & 4 \\
\hline
\end{tabular}

Note. Based on a 5-point rating scale with $5=$ very important and $1=$ very unimportant.

\section{Conclusion and Recommendations}

A panel of 20 volunteer directors contributed to the development of the 42 competencies identified over three rounds of iteration. Although the questionnaire was distributed to experts across Mississippi, actual respondents represented affiliates of state, national, and international organizations based in the Starkville area. Therefore, the results of this Delphi conducted as a preliminary stage of a larger study should not be generalized past the scope of this research. However, it should be noted, the desired 20-member panel, as suggested by Reid (as cited by Mullen, 2003), and a 70\% response rate ( $n \geq 16)$ was achieved increasing statistical strength of the Delphi study (Bradfor, 1996). 
Over three rounds of iteration 82 competencies were combined with like terms, or eliminated for not meeting the determined criteria, to a final list of 42 competencies and skills volunteer leaders should possess. Although current literature suggests there is a lack of leadership in non-profit and volunteer-based organizations (Cooperation, 2007b; Gibelman \& Gelman, 2001), the results of the Delphi suggest the panelists have specific expectations for the volunteers who lead their organizations. Having an understanding these volunteer leadership competencies and skills allows organization administrators, and leadership educators, the opportunity to tailor professional development efforts to the needs of the organization and volunteers who are involved.

Tuckey et al., (2012) states there is limited literature on the specifics of volunteer leader competencies, creating a noted limitation of this study. However, it is important, and encouraging, to note a handful of competencies identified by the panel of experts matched items mentioned by various other researchers in the field (Sanker, 2003; Goleman et al., 2002; Collins, 2001). The panelists all identify competencies such as integrity, emotional connectedness (compassion), authenticity (willingness to serve), and respect for others as components of an effective leader. Also, the identified list contained competencies and skills that are operational as well as leadership-based supporting Bowers's (2012) statement about organizations relying on volunteers to undertake both types of roles.

Practically speaking, 41 leadership competencies and skills can be overwhelming for a volunteer stepping up into a leadership position. Even with the addition of a factor analysis to this study, no item could be removed from the assessment. Because all of the items loaded onto one factor, it can be concluded that all 41 competencies and skills describe an aspect of leadership, supporting the objective of the study to determine what leadership competencies and skills volunteer directors desire in their volunteer leaders.

With regards to what measures should be used to assess leadership competencies and skills in volunteer leaders, the experts reached consensus on nine items. These items included: leader follow-through, communication with general volunteer population, return rate of volunteers, confidence in skills taught, feedback for other volunteers, observations, interactions with other volunteers, responsiveness of general volunteer population to react to leader's call to action, and ability to obtain quality volunteers. These assessment measures match the components of a 360-degree evaluation by multiple individuals from all levels of the organization, a method that is gaining popularity in the non-profit and volunteer-based sector (Culp et al., 2009; Hernez- Broome, \&Hughes, 2004).

\section{Recommendations for Practitioners}

Because the list of competencies and skills is so extensive, practitioners should identify items from the list that fit their particular volunteer leaders and the organization as a whole, supporting Hernez-Broome and Hughes (2004) notion that the volunteer leadership goal is to capitalize on the leader's strengths while reducing their weaknesses. This recommendation supports suggestions by Intagliata et al., (2000), that not all leadership competencies will support the organization's specific goals, and Henez- 
Broome and Hughes (2004) conclusion that it is impractical for all leadership to possess the same set of skills. Therefore, it is unrealistic to expect mastery of all competencies and skills identified by the Delphi. Still, it is important to provide developmental opportunities specific to the organizational and volunteer need.

\section{Recommendations for Further Research}

This Delphi study should be replicated with a panel representing organizations of varying size from a variety of locations across the country to determine its applicability on a larger scale. Because the panel of experts only represented local affiliates of regional and national organizations in the Starkville area one cannot assume the competencies and skills identified apply to volunteer leaders in all non-profit and volunteer-based organizations. Moreover, because the criteria for elimination was raised in the second round, replication is needed to confirm the inclusion of the 41 competencies and skills identified by this study.

The panel was comprised of directors from non-profit and volunteer- based organizations. The Delphi instrument included questions asking the respondents to state their names, affiliated organizations, and position titles for the purpose of monitoring data collection, however, no other demographic information was collected. When replicating this study care should be taken to gather demographics for further analysis. Demographic information can be analyzed to determine if age, gender, years in supervisory position, or organization affiliation impact what leadership skills the directors look for in their volunteer leaders.

\section{References}

Adler, M., \& Ziglio, E. (1996). Gazing into the oracle: The Delphi method and its application to social policy and public health. Jessica Kingsley Publishers.

Boezeman, E. J., \& Ellemers, N. (2014). Volunteer leadership: The role of pride and respect in organizational identification and leadership satisfaction. Leadership, 10(2), 160-173.

Bowers, K. M. (2012). An exploration of the leadership behavior of volunteer leaders. Retrieved from https://login.proxy.library.msstate.edu/login?url=http://search.proquest.com/docvi ew/1115317132? accountid=34815

Boyd, B. L. (2003). Identifying competencies for volunteer administrators for the coming decade: A national Delphi study. Journal of Agricultural Education, 44(4), 47-56. doi: 10.5032/jae.2003.04047 
Bradfor, B. D. S. (1996). The Delphi method: a useful tool for the allied health researcher. British Journal of Therapy and Rehabilitation, 3(12).

Cnaan, R. A., and Cascio, T. A. (1999) Performance and commitment: Issues in management of volunteers in human service organizations. Journal of Social Service Research. 24, 1 - 37. doi: 10.1300/J079v24n03_01

Conger, J. A. (1999). Charismatic and transformational leadership in organizations: An insider's perspective on these developing streams of research. The Leadership Quarterly, 10(2), 145-179. doi: 10.1016/S1048-9843(99)00012-0

Cooperation of National \& Community Service. (2007a, April). Issue brief: Volunteer retention. Retrieved from http://agweb.okstate.edu/fourh/focus/2007/may/attachments/VIA_brief_retention. pdf

Cooperation of National \& Community Service. (2007b, July). Volunteering reinvented: Human capital solutions for the nonprofit sector. Retrieved from http://www.nationalservice.gov/pdf/07_0719_volunteering_reinvented.pdf

Culp III, K., Brown, J., Hall, C., McDonough, K., Ragland, K., Weaver, C., \& Whitson, K. (2009). 360-Degree evaluations: A new tool in Extension programming. Journal of Extension, 47(3). Retrieved from https://joe.org/joe/2009june/tt7.php

Dawson, M. D., \& Brucker, P. S. (2001). The utility of the Delphi method in MFT research. The American Journal of Family Therapy, 29, 125-140. doi: $10.1080 / 01926180126229$

Dillman, D. A. (2011). Mail and Internet surveys: The tailored design method-2007 Updated with new Internet, visual, and mixed-mode guide. John Wiley \& Sons.

Farmer, S. M., \& Fedor, D. B. (2001). Changing the focus on volunteering: An investigation of volunteers' multiple contributions to a charitable organization. Journal of Management, 27(2), 191-211. doi: 10.1177/014920630102700204

Gines-Rivera, A. (2010). A needs assessment of pastoral counselors in honduras: A delphi study (Order No. 3405789). Available from ProQuest Dissertations \& Theses Global. (288241113). Retrieved from https://login.proxy.library.msstate.edu/login?url=https://search.proquest.com/docview/2 $\underline{88241113 \text { ? accountid }=34815}$

Goleman, D., Boyatzis, R., \& McKee, A. (2013). Primal leadership: Unleashing the power of emotional intelligence. Harvard Business Press.

Gordon, T., \& Pease, A. (2006). RT Delphi: An efficient, "round-less" almost real time Delphi method. Technological Forecasting \& Social Change, 73, 321-333. doi: 10.1016/j.techfore.2005.09.005 
Holloway, J. B. (2012). Leadership Behavior and organizational climate: An empirical study in non-profit organization. Emerging Leadership Journeys, 5(1), 9-35. doi: 10.1108/01437730710752229

Hsu, C. C, \& Sanford, B. A. (2007). The Delphi technique: Making sense of consensus. Practical Assessment, Research \& Evaluation, 12, 1-8. doi: 10.1016/S01692070(99)00018-7

Hernez-Broome, G., \& Hughes, R. J. (2004). Leadership Development: Past, Present, and Future. Human Resource Planning, 27(1), 24-32.

Intagliata, J., Ulrich, D., \& Smallwoood, N. (2000). Leveraging leadership competencies to produce leadership brand: Creating distinctiveness by focusing on strategy and results. People and Strategy, 23(3), 12.

Linstone, H. A., \& Turoff, M. (Eds.). (1975). The Delphi method: Techniques and applications (Vol. 29). Reading, MA: Addison-Wesley.

Ludwig, B. G. (1994). Internationalizing Extension: An exploration of the characteristics evident in a state university Extension system that achieves internationalization (Doctoral dissertation, The Ohio State University).

Mayburry, T. (2010). Identification of Industry Needs with Hospitality Management Curriculum Development: A Delphi Study. ProQuest LLC. 789 East Eisenhower Parkway, PO Box 1346, Ann Arbor, MI 48106.

Mullen, P. M. (2003). Delphi: myths and reality. Journal of health organization and management, 17(1), 37-52. doi: 10.1108/14777260310469319

Northouse, P. (2013). Leadership: Theory and practice (6th ed.). Thousand Oaks, California: Sage Publications, Inc.

Okoli, C, \& Pawlowski, S. D. (2004). The Delphi method as a research tool: An example, design considerations, and applications. Information and Management, 42, 15-29. doi: 10.1016/j.im.2003.11.002

Pearce, J. L. (1993) Volunteers: The organizational behaviour of unpaid workers. London/New York: Routledge

Pierce, I. J. (2007). The unique and essential characteristics of effective ethical leadership in for-profit and not-for-profit organizations: A Delphi study (Vol. 68, No. 02).

Rowe, G., \& Wright, G. (1999). The Delphi technique as a forecasting tool: Issue and analysis. International Journal of Forecasting, 75(4), 353-375. doi: 10.1016/S0169-2070(99)00018-7 
Sankar, Y. (2003). Character not charisma is the critical measure of leadership excellence. Journal of Leadership \& Organizational Studies, 9(4), 45-55. doi: 10.1177/107179190300900404

Schmidt, R. C. (1997). Managing Delphi surveys using nonparametric statistical techniques. Decision Sciences, 28,163-11 A. doi: 10.1111/j.15405915.1997.tb01330.x

Skulmoski, G. J., Hartman, F. T., \& Krahn J. (2007). The Delphi method for graduate research. Journal of Information Technology Education, 6, 1-21. doi: 10.1.1.151.8144

Small, E. E. (2007). Shared leadership: A social network analysis. Retrieved from http://search.proquest.com/docview/304830042? accountid=34815

Texas AgriLife Extension. (n.d.). Empowering volunteers to lead extension educational programs [PowerPoint slides]. Retrieved from odfiles.tamu.edu/odfiles/volunteer/.../empowering_volunteers.pptx

Tuckey, M. R., Bakker, A. B., \& Dollard, M. F. (2012). Empowering leaders optimize working conditions for engagement: a multilevel study. Journal of Occupational Health Psychology, 17(1), 15. doi: 10.1037/a0025942

Yousuf, M. I. (2007a). The Delphi technique. Essays in Education, 20(2), 80-89.

Yousuf, M. I. (2007b). Using experts' opinions through Delphi technique. Practice, Assessment, Research, \& Evaluation, 12(4), 1-8.

\section{Author Biographies}

Dr. Carley Morrison (carley.c.morrison@msstate.edu) is a visiting assistant professor of agricultural education, leadership, and communications (AELC) at Mississippi State University. Carley teaches undergraduate and graduate courses, and advises students pursuing degrees in agricultural science and AELC. Her research focus is non-profit leadership, as well as, student success and community engagement.

Dr. Laura Greenhaw (laura.l.greenhaw @ msstate.edu) is an assistant professor of agricultural education, leadership, and communications (AELC) at Mississippi State University. Laura teaches undergraduate and graduate courses, advises students in the leadership concentration of the AELC major, and directs the Thad Cochran Agricultural Leadership Program (TCALP) for the MSU Extension Service. Her research interest is in designing experiences that develop critical thinking skills and dispositions in learners. 